\title{
CONTENT AND LANGUAGE INTEGRATED LEARNING (CLIL): AN EXPERIMENTAL STUDY ON CLIL COMPATIBILITY WITH THE MODERN GREEK EDUCATIONAL SYSTEM
}

\author{
Catherine Georgopoulou-Theodosiou \\ Department of Electronics Eng., T.E.I. of Piraeus, Egaleo 12244, Greece \\ E-mail: catgeo@hotmail.gr
}

APA Citation: Theodosiou, C. G. (2016). Content and Language Integrated Learning (CLIL): An Experimental Study on CLIL Compatibility with the Modern Greek Educational System. English Review, 4(2), 149-160

Published: 01-06-2016

\begin{abstract}
This paper focuses on the Content and Language Integrated Learning (CLIL) method for (foreign) language teaching. The CLIL approach is rapidly gaining momentum across Europe and all over the world. It is the result of recent European Union efforts to develop and apply innovative educational practices of interdisciplinary character in order to bridge the gap between foreign language education and optimum learning outcomes. In order to investigate the compatibility of CLIL with the contemporary Greek educational reality, a small-scale experimental research study was set up, including the development of original e-learning material, a pilot class instruction based on this material and the evaluation of the results. The class instruction was based on Project-Based Learning whereas Collaborative Learning was supported by the Edmodo e-learning platform. Information on the progress of the pilot class instruction and the learning outcomes achieved was disseminated through a wiki set up for this task.
\end{abstract}

Keywords: CLIL, interdisciplinarity, plurilingualism, multiculturalism, assessment, Information and Communication Technology (ICT)

\section{INTRODUCTION}

In their effort to achieve economic success based on mobile multilingual populations, countries across the globe and the European Union in particular, are recently expressing a great interest in human capital. Linguistic capital is one of the most important components of human capital. Multilingualism and the support as well as the preservation of linguistic diversity in Europe are among the main goals of the European Union's language policy. Indeed, EU policy states that all European citizens should learn to communicate and use at least three languages -'Mother tongue plus two other languages' - and that teaching must start at an early age (Barcelona Declaration, 2002). The clearest indication of this interest is the appointment of a Commissioner for Multilingualism in January 2007.

In the discussion on how to achieve the above goals while providing a quality education for all citizens, the CLIL method and its future developments play a central role. As CLIL develops and expands, it is linked to the educational evolution accompanying economic and sociopolitical changes, bringing with it opportunities and challenges worth taking. Integrating language with non- 
language content, in a dual-focused environment, has emerged as a solution, the most obvious advantage being that exposure to a foreign language does not need any extra time within the curriculum. It is more than the desire of governments, parents and the educational community to equip young people with higher competence in languages what promotes the CLIL approach. It is the very nature of the CLIL method, an educational innovation which suits the times, needs and aspirations of learners, that justifies the expectations for a huge impact in the near future. Learners nowadays are increasingly unwilling to learn now for use later; they prefer to learn and use now, which suits the immediacy of purpose common in our times. Globalization, mobility, technology and assessment issues are also considered likely to have a further impact on learners' attitudes towards how they learn, particularly with regard to foreign language learning.

CLIL's four major components, the 4Cs (Coyle, 2010), Content (subject matter), Cognition (learning and thinking processes), Communication (language learning and using) and Culture (developing intercultural understanding and global citizenship) clearly underpin the conclusion that CLIL method is not just another way of learning a foreign language, but an innovative educational process that integrates major contemporary learning theories. Within this framework of theoretical background and pedagogical method, the two research questions investigated through this project were (i) how efficient is the use of ICT technology as a supportive tool in CLIL-based class instruction, and (ii) whether CLIL is compatible with the contemporary Greek educational system.

\section{METHOD}

The 'EAT WELL - BE HEALTHY'

project, designed and developed as a CLIL method application, took place in the 20th primary school of Ilioupolis, a typical public school in the city of Athens, Greece, where English is taught as a foreign language four times a week in 40 or 45 -minute sessions. The $5^{\text {th }}$ and $6^{\text {th }}$ grades of this school, each consisting of about 20 pupils, served as the research and the control group, respectively. The class instruction based on CLIL was designed and implemented by the author of this paper working as an English language teacher at the school. It lasted for eight weeks (April - May 2015) using English as the medium language and involving the following subject areas: (i) Informatics, (ii) English language teaching and (iii) PSHE (Personal \& Social Health Education).

The students worked in five groups of mixed ability levels, following the steps and instructions of project based learning to foster learner motivation through an interdisciplinary approach to knowledge. The main goal of the project was to promote healthy diet and good eating habits as a necessary component of students' knowledge about life, health and wellness. The educational objectives were based on Bloom's Revised Taxonomy of educational goals and were divided into cognitive, affective and psychomotor, as indicated. The teacher resources were all gathered for reasons of convenience into a mind mapping software available through https://www.mindmeister.com $L$. The original work and material created by the students during this project were both digital and analogue, as they can be seen in the video available in http://www.kizoa.com/, a free web 
ENGLISH REVIEW: Journal of English Education Vol. 4, Issue 2, June 2016

2.0 tool. Some of them were crafts and posters for the class; other forms included recordings, digital storytelling works, publications, electronic posters and power point presentations.

The Lesson Plans created were

four (4) to correspond to the four objectives (4Cs) of the CLIL approach. According to Coyle $(2000,2007)$ they are absolutely significant for the educational process which is based upon them differentiating this method from traditional foreign language teaching. The specific objectives and corresponding activities are described below:

- Content: Students are expected to fulfill the objectives of the curriculum for the subject area taught with the CLIL method, enriching their knowledge by studying the content from different
ISSN 2301-7554

https://journal.uniku.ac.id/index.php/ERJEE

angles allowing more depth and understanding on the area concerning nutrition and health.

More specifically, in the first Unit entitled 'Eat a Rainbow', the research group of students were invited, among other things, to work online on a collaborative digital canvas, which is provided by the web tool

$2.0 \mathrm{www}$.linoit.com and is available online

at: http:/ / linoit.com/users/catherinegeo/canvases/EAT\%20A\%20RAINBOW . On the canvas, they had to match the nutritional value of foods with their origin and benefits, adding comments and observations, an activity which the control group of students performed in the classroom, with fewer chances for adding comments or for information search at home. Picture 1 shows an aspect of the electronic canvas.

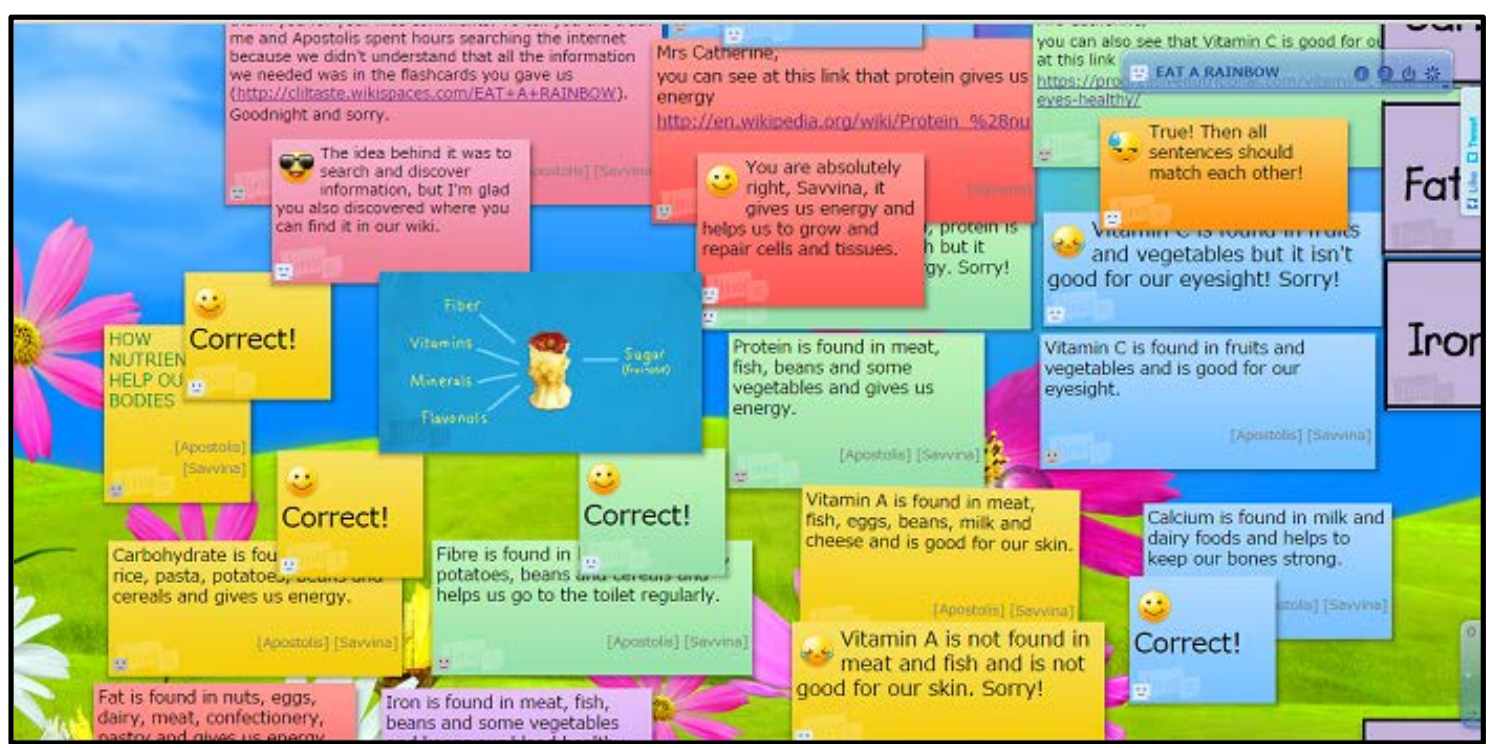

Picture 1. Aspect of the collaborative digital canvas

- Communication: Students are expected to understand and communicate in the target language on issues related to nutrition, acquiring greater awareness of both mother tongue and the target language - by practising communication skills and developing a positive attitude towards plurilingualism.

In the second Unit entitled 'My eat well plate', the students of both classes 
were asked to work in groups in order to design and present a healthy dish and then to be recorded during the description of their healthy dishes.

Participation in this activity came from both teams and the final digital storytelling product, available by the web 2.0 tool www.utellstory.com can be visited at the web address: http://www.utellstory.com/vie wstory/view/8ae80672f14123ba65e590b b2da83989\#player.
- Cognition (Knowledge): Students are expected to develop cognitive skills and mental processing of information on healthy eating and other subject areas, strategies of an active learning approach to knowledge through critical and creative thinking and development of lifelong pursuit of language learning.

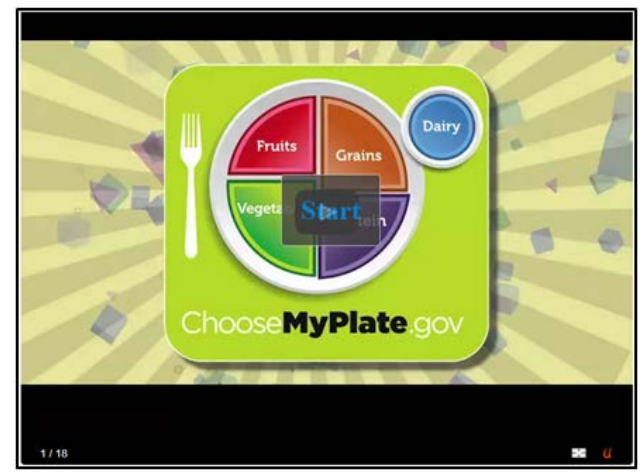

Picture 2. Aspect of the digital storytelling web tool

In the third Unit, entitled 'Do you like Bread?', students of both groups were asked to create in groups their own recipes and present them to class, an activity that ended up in an electronic recipe book as a final product with the support of the web tool

2.0 www.issuu.com. It is available at the web

address: https://issuu.com/catheringeo/docs/final_cookbook.

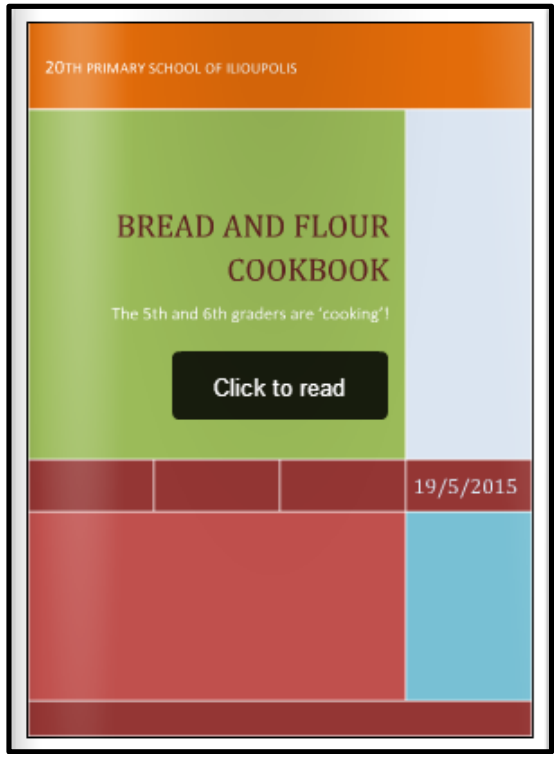


Picture 3. Aspect of the electronic recipe book

- Culture: Students are expected to understand their own culture compared to the culture of other people, fostering intercultural knowledge, respect, tolerance towards diversity, not only in the area of nutrition but of various other issues, as well.

For the fourth Unit entitled 'Food around the World', the students of the research group were invited to create, among other things, a digital interactive poster presentation in which they recorded their opinions and comments on the problem of world hunger, malnutrition and on appetite disorder issues such as bulimia nervosa and anorexia nervosa. The electronic poster provided by the web tool 2.0 www.glogster.com is available at the web address: http://catgeo.edu. glogster.com/world-hunger/. The students of the control group expressed their views on the above issues in a classroom discussion and created analogue posters at school. Picture 4 presents the collaborative work of the students of the research group on the digital poster.

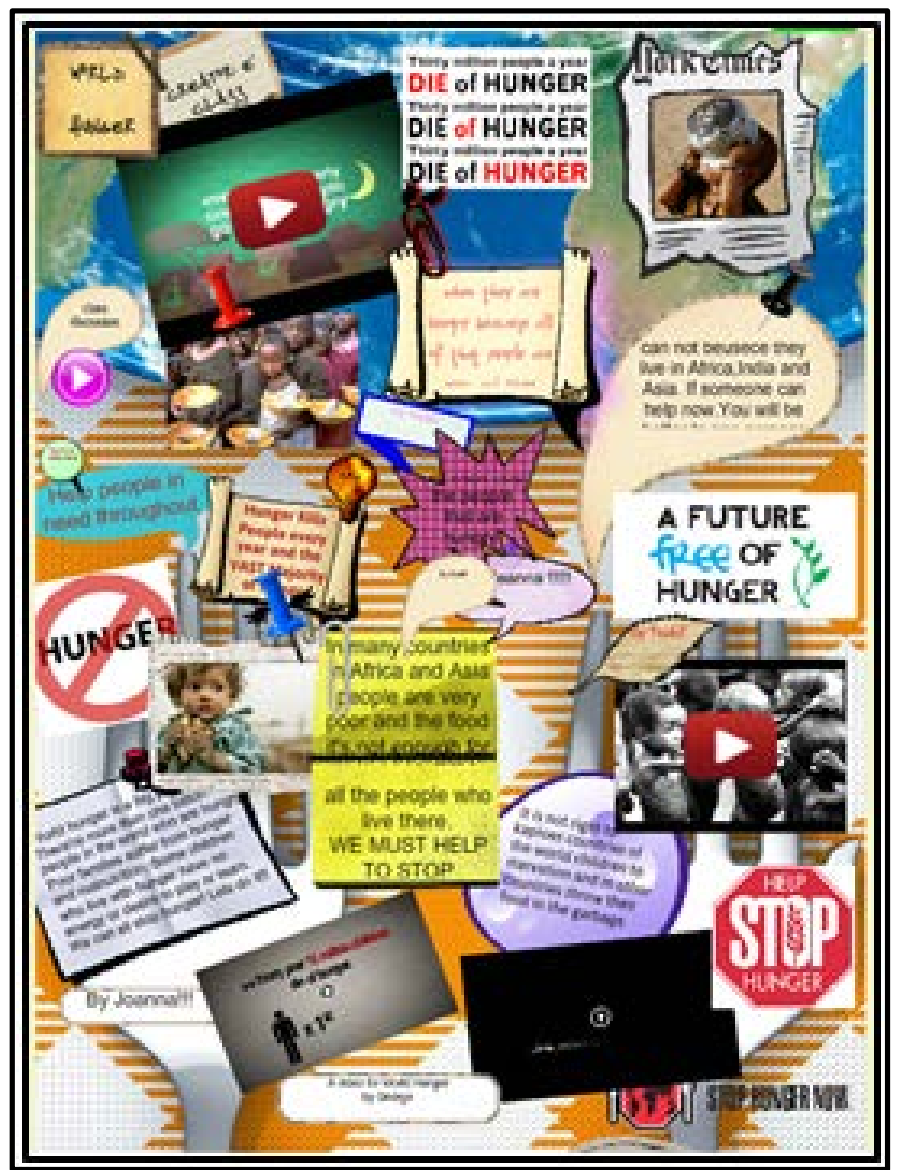

Picture 4. Aspect of the collaborative digital poster

The teacher's comments and critical thinking were saved in a digital diary available through https://penzu.com/.

\section{Educational platforms and e-learning material}

Educational platforms and elearning material were both employed in 
the specific project to support collaborative learning and enhancement of learning outcomes for the students. More specifically, the educational platforms were two. The first one, Edmodo (for more information visit the web

address: https://edmo.do/j/3x6hpq), is a social learning network (the so-called 'Facebook of pupils') that offers collaboration and coaching tools to K-12 schools and teachers. Edmodo is included in the list of "The Top Apps for Teachers" published by the PC Magazine in 2013. Picture 5 shows the Edmodo platform interface. The second platform developed for this project is a wiki called "CLIL TASTE" (visit the wiki at the web address: https://cliltaste.wikispaces.com $\angle$ WHAT+IS+CLIL\%3F), a tool that promotes collaborative learning and enhances learning outcomes. This is shown in Picture 6.

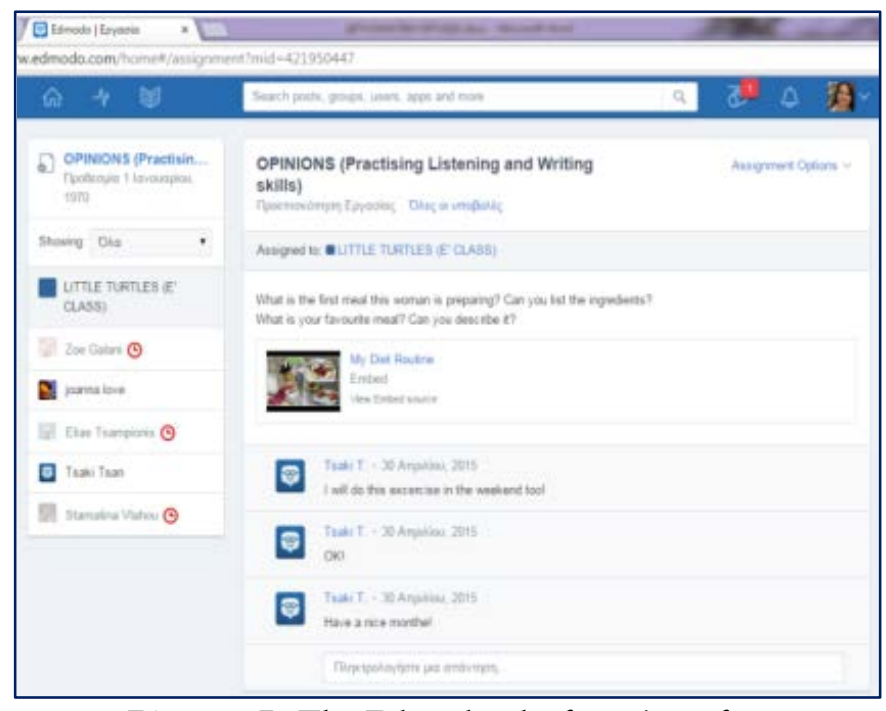

Picture 5. The Edmodo platform interface

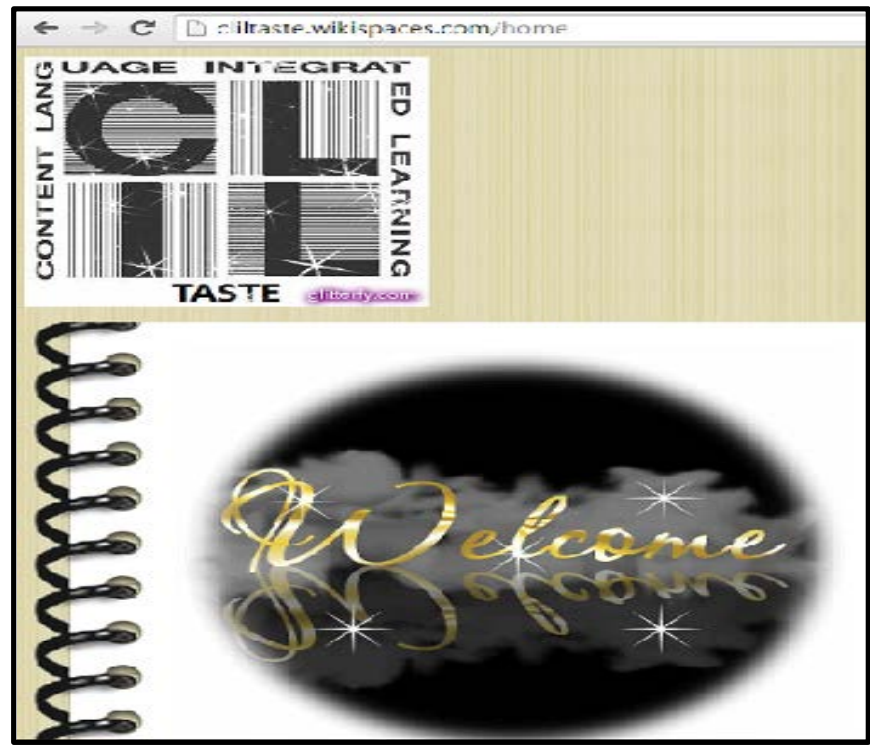

Picture 6. Aspect of the wiki's interface 
ENGLISH REVIEW: Journal of English Education Vol. 4, Issue 2, June 2016
ISSN 2301-7554

https://journal.uniku.ac.id/index.php/ERJEE

\section{RESULTS AND DISCUSSION}

1. Assessment

Starting with the project assessment, the procedure followed was the one indicated and promoted by the relevant instructions of the Greek national curriculum which suggests three forms of assessment: initial, formative and summative. Digital and analogue questionnaires were given to the students to assess (i) their prior knowledge on the subjects dealt with and (ii) the degree of assimilation of new material and teaching input with or without the support of technology (project and control group respectively). A common framework of assessment, especially designed and used in CLIL, that integrates content at different complexity levels, functions and cognitive skills, was employed for the evaluation of results of the teaching intervention (Barbero, 2012). It is based on the knowledge framework by Mohan (1986), a taxonomy where knowledge is considered in relation with language at three different levels: (1) classification /concepts, (2) principles/processes, and (3) evaluation/creation. The assessment suggested by Mohan recommends "scale classified criteria" (Matsagouras, 2004) or the so-called rubrics and focuses on how language is incorporated into the content in different difficulty levels of cognitive and academic requirements (CALPCognitive Academic Language Proficiency). The rubrics were adapted in the Greek language by the instructor and author of this article to accommodate the age group of students and educational objectives of the project.

\subsection{The Leuven scale}

The Leuven scale (Laevers, 2005) is a standard instrument to measure the degree of well-being and the degree of involvement of learners during an educational process, which was also used for the assessment of the class instruction. According to the creator, both well-being and involvement are important during the educational process as they ensure a quality and an optimal relation of students with the environment and therefore a successful deep level learning and development.

\subsection{The CLIL Matrix}

A crucial thing in CLIL is to assess both language and communication skills and assimilation of content, a demand that is very difficult to satisfy as they are integrated into each other to produce the expected outcome. The most successful evaluation approach to assess the quality and analyse the integration of cognitive and linguistic levels in activities and materials used during a lesson employing the CLIL methodology has been adapted by professor Do Coyle (2002) from Cummins' work (1984). It is a key tool named CLIL Matrix which teachers adopting the CLIL approach find quite useful as a means of evaluating their educational material, of the students' progress in both the linguistic and cognitive domain alike and as a guide towards improvement of learning material in the future. It consists of four (4) quadrants to assess a single task, a sequence of tasks or even the quality and output of a whole unit in the teaching procedure. Positioning tasks in the quadrants helps us analyse and ascertain the type of task and the balance between the task and the learner's performance and needs. The matrix allows an overview of the learning progress in terms of linguistic and cognitive development. Picture 7 shows a simple CLIL Matrix but there is a more informed awareness-raising tool created by an international team of CLIL experts, which cross-combines content, language, integration and learning with culture, 
communication, cognition and community. It is composed of 16 indicators which lead to examples and a number of questions for CLIL teachers to answer about their own teaching at the following web address: http://archive.ecml.at/mtp2/cl ilmatrix/EN/qMain.html.

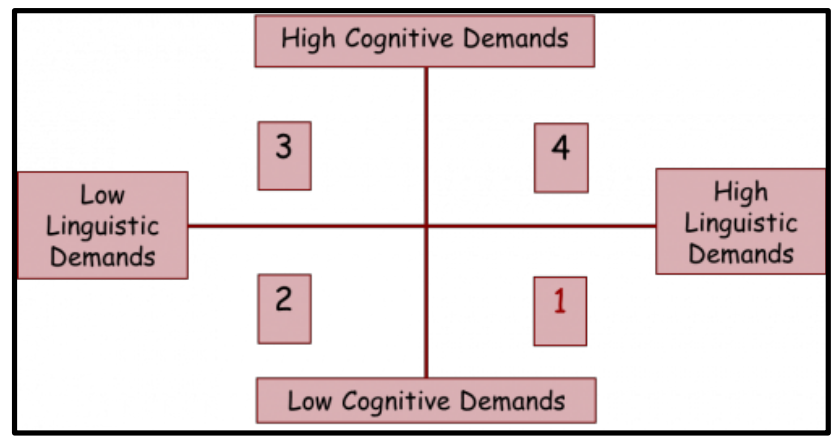

Picture 7. The CLIL Matrix

As one can notice in Picture 8, the final depiction of the CLIL Matrix was formed by the assessment of the educational material and the project activities. The conclusions could be processed if we followed the arrow, which charted the course of each unit in relation to the cognitive and language aims and objectives set beforehand. An interesting observation that could be made was that there was a decline in interest and involvement in the beginning of the intervention, as the Leuven indicators also marked, created as a result of the exclusive use of the target language and the abundance of stimuli during the teaching of the first unit. For that reason, it was considered appropriate for the second unit to maintain cognitive and language requirements at a lower level in order to normalise the process of assimilation of content and new language requirements in the foreign language. The remaining modules seamlessly evolved steadily rising while fulfilling the expectations and anticipated outcomes of the students' performance.

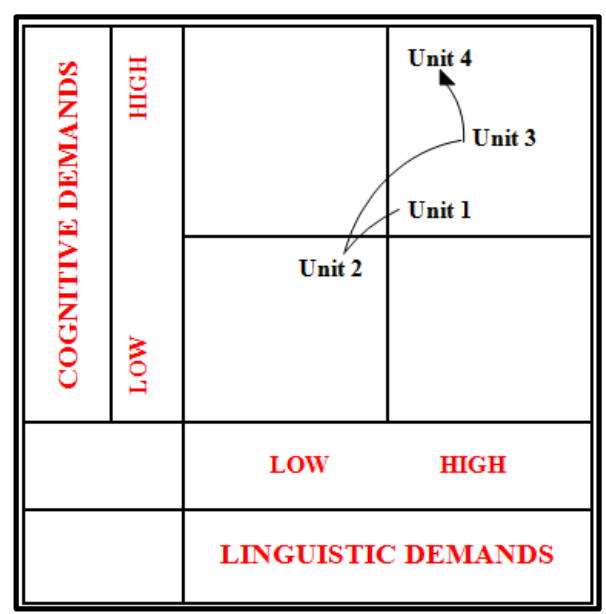

Picture 8. Schematic representation of the assessment of the learning material of the project with the use of the CLIL Matrix 
An interesting result obtained through the assessment and evaluation procedure of this project is that the engagement with technology leads to understanding and assimilation of the content of teaching to the same degree or extent as does the traditional teaching method without any technological support. Where technology does make a difference, though, is in rendering learning more enjoyable and interesting and thus providing incentives and increased motivation for learning. As regards (foreign) language learning with technological support, our results show that students (i) individually interacted with technology (active learning), (ii) developed technological skills, (iii) managed to enhance their performance and (iv) ultimately gained more opportunities for language acquisition and communication.

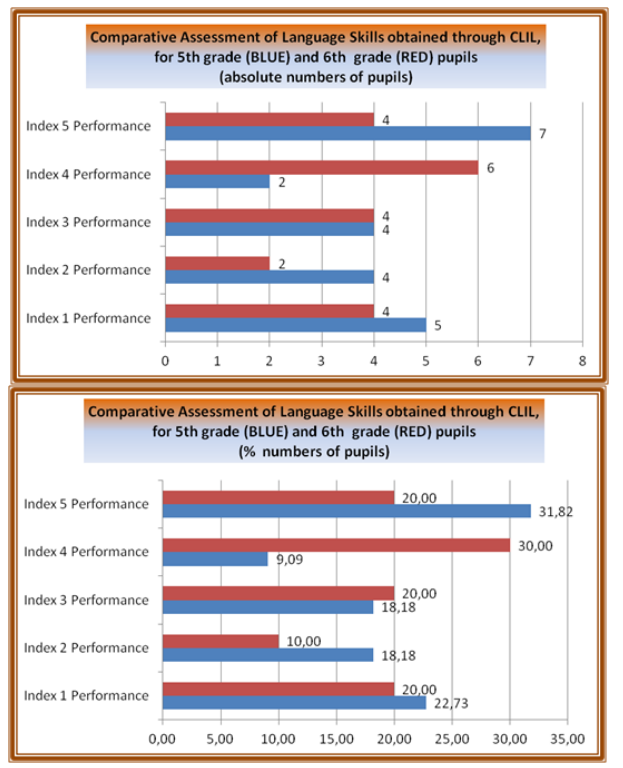

Picture 9. Tables of comparative assessment of Language skills delivered through CLIL

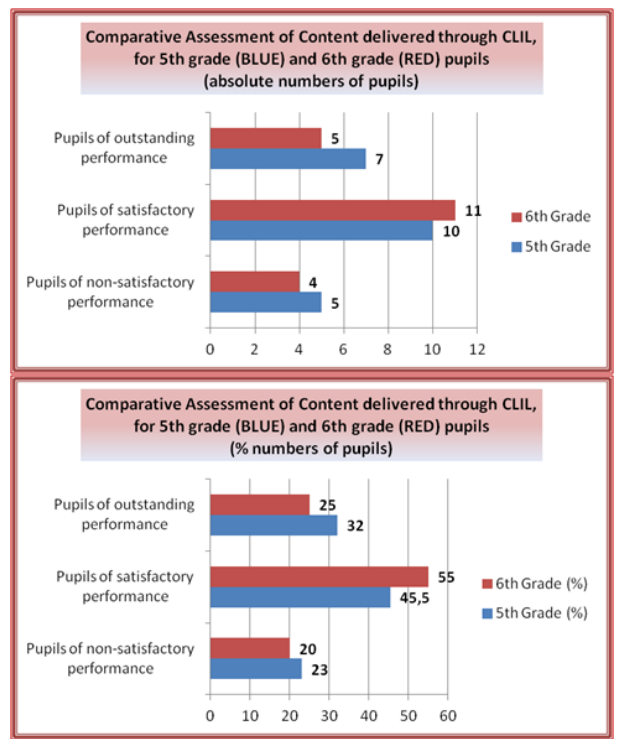

Picture 10. Tables of comparative assessment of Content delivered through CLIL 
The advantages of the approach are listed below along with some more thoughts that best describe the dynamics of the approach:

- Background knowledge of the English language in Greece renders the introduction of CLIL methodology easier.

- CLIL promotes linguistic and cultural diversity and the development of a European identity.

- Project-based learning and Technology positively enhance the approach.

- The introduction of the approach with low exposure to foreign language is considered advantageous if taught in a way appropriate to children's age (Llinares, 2005).

- CLIL helps learners better conceive even the use of mother tongue, namely to go deeper into the operating mechanisms of the two language systems (Sanz, 2000).

- CLIL is very useful for young learners who "use language to learn" and "learn to use language"(Marsh, 2002).

There are, however, a number of disadvantages coming from the implementation of the approach summarised below:

- The demands on teachers are increased with respect to the preparation for the lesson and the development of the appropriate material.

- At present, the CLIL method does not lead to any certification of knowledge, at least in Greece.

- The method should be disconnected from the teaching of English to fully develop its dynamics.

- Its adoption implies an increase in the time dedicated to foreign language teaching in the school timetable, which creates problems because of the pressing time limitations.

- Teachers' training, both in a specific subject area and in the teaching of a foreign language, requires time and money.

- The implementation of the method requires reforms in the school timetable up to the national curriculum and educational policy towards foreign language teaching, prerequisites which take time and are difficult to accomplish for various reasons.

\section{CONCLUSION}

The conclusions following are based on this small-scale educational intervention and the experimental study of the CLIL approach at a school and reflect the writer's personal ideas. They can be summarised in the following remarks:

- The adoption of the CLIL approach would upgrade primary education in Greece, mainly by reinforcing the substantial contact of students with a foreign language.

- There is an urgent need for training of educators involved in CLIL and their participation in online communities for information and support.

- Countries worldwide respond to the need for increase of their linguistic capital through a series of policies concerning languages and CLIL can help transform these educational policies into reality.

- Teachers' and students' satisfaction from the implementation of CLIL, both in Greece and Europe, paves the way for further research on this approach, that could end up to a comprehensive proposal to the State.

- The adoption of alternative educational models, better suited to 
the target content per case, is another suggestion.

- The introduction of the CLIL method merits serious consideration in the context of both (foreign) language teaching reform and the country's more general planning and development policies.

- The vision of CLIL is to promote linguistic and cultural experiences for every person providing inclusion and the privileges of plurilingualism and multiculturalism.

The results mentioned above support a positive answer to the second research question: the CLIL approach is compatible with the modern Greek public schools, even at the (pre-)primary education grades. An educational policy that considers CLIL as a realistic solution to the European and universal need to upgrade formal education and invest in education for the benefit of society can clearly be adopted in modern Greece. CLIL emerges as a practical and sustainable solution with additional social, psychological and economic benefits. It is a solution compatible with the European policy and its goals which needs to be given a serious consideration.

\section{REFERENCES}

Anderson, L., Kratwohl, D., Airasian, P., Cruikshank, K., M ayer, R., Pintrich, P., Raths, J., Merlin, C., \& Wittrock, M. (2001). A Taxonomy for Learning, Teaching, and Assessing: A revision of Bloom's Taxonomy of Educational Objectives. New York: Longman.

Barbero, T. (2012). Assessment tools and practices in CLIL. In Assessment and Evaluation in CLIL.

Barbero, T. \& Maggi, F. (2011). Assessment and Evaluation in CLIL, in Marsh D., Meyer O., Quality

Interfaces, EAP. Eichstätt: Eichstaett

Academic Press UG

Bloom, B. S. (ed.).Taxonomy of

Educational Objectives. Vol. 1:

Cognitive Domain. New York:

McKay, 1956.

Coyle, D., Hood, Ph., \& Marsh, D. (2010).

CLIL, Content and Language

Integrated Learning. Cambridge:

Cambridge University Press.

Cummins, J. (1984). Bilingualism and Special Education: Issues in Assessment and Pedagogy. Clevedon: Multilingual Matters.

Cummins, J. (2000). Language, Power and Pedagogy. Clevedon: Multilingual Matters.

EUR-Lex (Access to European Union law). Communication from the Commission to the Council, the European Parliament, the Economic and Social Committee and the Committee of the Regions - Promoting Language Learning and Linguistic Diversity: an Action Plan 2004 2006. Retrieved from the web address: http://eurlex.europa.eu/legalcontent/EN/TXT/?uri=CELEX:52 003DC0449

European Comission. (Eurydice network). (2008). Key Data on Teaching Languages at School in Europe. Retrieved from: http:/ / eacea.ec.europa.eu/about/ eurydice/documents/KDL2008_E N.pdf

Eurydice. (2006). Content and Language Integrated Learning (CLIL) at School in Europe. European Commission. Retrieved from: http://www.indire.it/lucabas/lk mw_file/eurydice/CLIL_EN.pdf

Ioannou, S., \& Pavlou, P. (2011). Guidelines for CLIL Implementation 
in Primary and Pre-primary Education.

Kilpatrick, W. H. (1918). The project method. Teachers College Record, 19, 319-335.

Krashen, S. (1981). Second Language Acquisition and Second Language Learning. Retrieved from the web address:

http://www.sdkrashen.com/ conte nt/books/sl_acquisition_and_lear ning.pdf

Laevers, F. (2005). (Ed. in collaboration with: Mieke Daems, Griet De Bruyckere, Bart Declercq, Julia Moons, Kristien Silkens, Gerlinde Snoeck, Monique Van Kessel) Well-being and Involvement in Care Settings. A Process-oriented Self-evaluation Instrument. Kind \& Gezin and Research Centre for Experiential Education. (Manual: http://www.kindengezin.be/img / sics-ziko-manual.pdf)

Llinares, G. A. (2005). An introduction to CLIL. Presentation at Cracow European Language Label Conference

Llinares, A., Morton, T., \&Whittaker, R. (2012). The Roles of Language in CLIL. Cambridge: Cambridge University Press.

Marsh, D. (2002). Content and Language Integrated Learning: The European Dimension - Actions, Trends and Foresight Potential. DG Education \& Culture, European Commission.

Maljers. A., Marsh, D., Coyle, D., Hartiala, A.K., Marsland, B., Pérez-
Vidal C., \&Wolff, D. (2002). The CLIL Compendium.

Mavromara, L. A. (2010). The Pedagogy of Project-based Learning (Project method) and its application in the teaching of a foreign language language specialty. PI Inspection of Educational Affairs, 17.

Mehisto, P. (2008). CLIL counterweights: Recognizing and decreasing disjuncture in CLIL. International CLIL Research Journal, 1(1), 93-120.

Mertler, C. A. (2001). Designing scoring rubrics for your classroom. Practical assessment, Research \& Evaluation. Retrieved from: http:/ / pareonline.net/getvn.asp?v $=7 \& n=25$

Ministry of Education. (2002).Cross Curriculum Framework (DEPPS) and Curricula (A.P.S.) of Compulsory Education. Volume I. Athens: Ministry of Education Pedagogical Institute.

Mohan, B. (1986).Language and Content. Massachussetts: Addison-Wesley Publishing Company.

Mohan, B., \& Van, N. M. (1997). Understanding cause-effect: Learning through Language. Forum, [Online] 35 (4).

Quartapelle F. (2012). AICLE/EMILE. Retrieved from: http:/ / www.aeclil.net/

Sanz, C. (2000). Bilingual Education Enhances Third Language Acquisition: Evidence from Catalonia. Applied Psycholinguistics, 21: 23-44. 